\title{
Study on Background of Music Education in Higher Normal Universities in China
}

\author{
Li Gong \\ Department of Music, Dezhou University \\ Dezhou 253023, Shandong, China \\ E-mail:kkiy@sina.com
}

\begin{abstract}
It was not until the earlier $20^{\text {th }}$ Century that music education in higher normal universities in China was born, and it started with the original intention of borrowing and learning western music content and forms. By analysis of historical literature review, this article is going to explore historical factors that have contributed to birth of music education in higher normal universities in China, get to the root of the history and take history as a mirror.
\end{abstract}

Keywords: Music, Normal education, Background, School songs, Aesthetic education theory

Since 1905 when the Qing Dynasty ordered to abolish the imperial examination, modern higher education in China has gone through more than a hundred years so far. Music education in higher normal universities in China has grown out of nothing and has developed closely in parallel with development of modern higher education in China. If calculated from 1920 when Beijing Female Higher Normal School opened the special training course of music education, the subject of music has actually gone through the history of higher universities merely for eighty years or so.

Chinese ancient traditional men of letters held an extremely narrow attitude towards music. According to them, among the numerous subjects of music, only Guqin might reflect the elegant sentiment of "meeting bosom friend at a high mountain with floating" and correspond with the temperament of their cultivating an original nature and paying attention to their own moral uplift without thought of others. Thus, Guqin has always received respect and protection from Chinese traditional men of letters. However, other musical performance arts were regarded as disgraceful entertainment for people in the consciousness of the national people, and could not be affirmed and attached importance to. Besides, in the later Qing Dynasty, social crisis and national crisis in China aggravated increasingly day by day, so people began to place the major task and focus of expanding the nation on developing industries and strengthening the national power and military power. The whole nation was really reluctant in psychology and too occupied to study western music arts, improve musical quality of the national people and develop music education.

As for any newly born object, the selection and custom of its culture determines it necessarily will experience a process of being accepted, being understood and being digested. During late Qing Dynasty, those with breadth of vision in China devoted themselves to saving the nation by reforming traditional educational system. Both Qing Government and those who run a school among the people imitated western higher educational mode to make a series of educational reforms, such as, reform of academy of classical learning, establishment of all sorts of special schools, abolishment of federal imperial examination system, release of gui-mao school system and holding of normal education, etc. Although all this has undergone a complicated process, the idea of separation of subjects in colleges and universities in China was ultimately realized, and higher education in China successfully switched from the traditional and unique educational target of beginning an official career to the modern training target of diversified specialty. Especially, the emergence of aesthetic education theory and prevalence of school song in the late $19^{\text {th }}$ Century and early $20^{\text {th }}$ Century enabled the subject of music to step towards the historical stage of higher normal education in China.

\section{Emergence of the idea of separation of subjects in higher colleges and universities}

Guo Songtao, the first ambassador of Qing Government in Britain and France, conducted an investigation from several perspectives into the educational systems in Britain and France in the name of a senior official of the country, and for the first time, he pointed out, the reason western modern higher educational system was superior to Chinese traditional educational system was that, western school educational system "focused on practical use and did not advocate empty 
words" (He Zhaowu, 1980, p535), and that, "pursuit of study and pursuit of official positions was separated into two." That is, those in pursuit of official positions entered the national affiliations, such as affiliations of military tactics and laws, and served all their life with what they had learned. (He Zhaowu, 1980, p535). Guo Songtao provided a crucial thought for people at that time to reform the traditional educational system in view of his recognition and publicity of differences between educational goals of Chinese and western countries.

Zheng Guanying, the representative figure of Reformation reformists, also put forward the thought of setting up universities with separated subjects in his "The Crisis Awareness in Millennium" in 1893. He proposed that in each school, "each subject should be learned by several classes, and discrimination should be conducted at the end of the year to decide going up and down on the part of students." "One subject should play a due role" and "each one should bring into play his capacity". Students should have their own advantages, so that objects they manufactured would be elegant, and utensils they made would be sharp; when they governed the nation, it would be rich, when they ruled soldiers, they would be powerful, when they made wealth, it would be adequate, and when they were engaged in business, it would be flourishing; There was nothing they could not govern or nothing they could not manage, and the nation would be prosperous and the people would be strong. In his "Chinese ERIC Thesaurus Construction and Format", Liang Qichao also put forward the proposal of setting up universities with separation of subjects. Educational thoughts of Reformers were mostly confined to a theoretical stage, and although they had been carried out on a certain scale, they finally became a flash in the pan due to failure of the political reform of Reformers.

In 1895, as one of the well-known minister of "Tongzhi Resurgence", Sheng Xuanhui also put forward the idea of setting up universities with separation of subjects to cultivate advanced professional talents. Different from others, he was not confined to theoretical comments, but put this idea positively into practice, which gained sufficient affirmation from the society. Under his direction, the first modern university with separation of subjects in China was established --Tianjin Chinese and Western School. Public class was assigned for first-class schools in the first year, including elementary subjects of geometry, triangle Pythagorean, physics, history of all countries, and translation of English, etc. From the second year, five special subjects were categorized, namely, engineering, electricity, mineralogy, mechanics and law. Practice of Sheng Xuanhui in the thought of separation of subjects in universities offered a good mode for modern educational reform in China.

In January 1904, the Qing Government released "gui-mou school system". It required definitely the thought of universities with separation of subjects in higher education, and stipulated that all schools "should be aimed at offering adequate talents in all sorts of academic fields and arts". Specialty was classified into eight subjects, namely, economic subject, political and law subject, literature subject, medical subject, physics subject, agricultural subject, engineering subject and business subject, from which students should select one as their major subject. That was the school system that was released formally for the first time in the history of Chinese education and was generally put into practice all over the country. Its release confirmed the fundamental mode and framework of modern Chinese school system and thoroughly practiced the idea of separation of subjects in the universities among each student.

Emergence of modern universities with separation of subjects signified that higher educational thought in China had changed fundamentally and higher education was directly interrelated with social production and social occupations. Although among the eight major subjects stipulated in "gui-mou school system", we haven't found any arrangement on Musicology, and not even the major of Piano, emergence and practice of the idea of universities with separation of subjects exactly has opened a window for music education to step into higher colleges and universities.

\section{Emergence of normal education in modern China}

The Qing Government ordered, all provincial examinations and metropolitan examinations had to be ceased from 1906, which was a historical transition for higher education in China. On one hand, abolishment of the imperial examinations and emergence of schools symbolized the fundamental reform of training of modern talents and the system of selection in China, and on the other hand, implied that modern higher education in China had fundamentally transited to modern education system in terms of the system. "It was determined by schools to select talents and officials" (Zhang Dan, 1963, p.3). Thus, the significant status of higher colleges and universities had been brought to light.

Although the tradition of respecting teachers and their teaching started from the ancient times in China, education had always been existing as dependency of political reign. In addition to recognizing the role of education in transmitting knowledge, people were indifferent to the development rules of education per se. the qualification of being a teacher lied in knowledge, and naturally those with knowledge had the qualification of being a teacher. "A learned man for a teacher" seemed to be an unalterable principle. Especially, in the feudal small-peasant economy society with handicraft industry being the primary industry and with low productivity, normal people who accounted for a large majority of the population were not entitled to education, development of elementary education was weak, and the society did not require a large number of teachers full of learning, let alone special educational institutions for training teachers. The interrogation of "what's the use to educate teachers" made it absurd and ridiculous to train teachers. As a result, in 1880 s, when introducing normal schools in foreign countries, most of ideologists acquainted with Chinese and western 
education had the thought of hunting for novelty, but there had never been any one who put forward the proposal to set up normal schools in China.

With release of new schools and abolishment of the imperial examination, new sorts of schools were extensively established all over China, ranging from higher education to elementary schools, and modern educational mode was unprecedentedly rapidly developed within the whole nation. According to statistics, the total number of the whole nation in 1902 was 6,912, and increased to 258,876 by the year 1905 (Zhou Yutong, 1934, p.137), with an increase of almost 37.5 times within the three years. In addition, according to the statistical education data formally released by the Academic Division of Qing Government, only the number of elementary schools in 1909 was over 170,000 more than that in 1907, and the number of students in elementary schools was approximately 614,000 more than that in 1907.

\section{Insert Table 1 Here}

Because the reaching system reform of late Qing Dynasty was conducted simultaneously at different educational levels, the large-scale growth of the number of schools and students and the brand-new teaching content brought modern Chinese education into a crisis of shortage of teachers. On one hand, the Qing Government took a positive attitude to bring in foreign teachers, and on the other hand, sent a large number of Chinese students to Japan to take the subject of teaching as an elective course. However, compared with the rapidly developed education scale of China, that still could not resolve the crying needs. Under such a circumstance, normal education made the ascent of the educational stage in China under direction of the idea of separating subjecting in universities.

The earliest normal education institution was the Teacher College set up in 1897 by Shanghai Nanyang Public School which was founded by Sheng Xuanhuai. However, the actual higher normal education was the Teacher's Training Faculty set up by the Imperial University of Peking in 1902. In 1904, the Qing Government released "School Regulation on Imperial Permission", which separately established normal education system, including the two classes of elementary normal schools and excellent normal schools, and regulations of both classes of normal schools categorized educational subjects as required public courses, particularly establishing such courses as didactics and teaching approaches of all subjects. Furthermore, in 1907, the Qing Government released "Women's Normal School Constitution". Afterwards, the Qing Government concentrated all its strength to develop normal schools with all subjects by successive abolishment of simple subjects, subjects of lecture and study and training institutes in normal schools in all provinces. Except for such remote border provinces as Tibet and Xinjiang, etc, excellent normal schools were constructed in succession in all provinces. Hence, modern normal educational system was initially set up in China.

\section{Popularization of school song and proposal of aesthetic education theory}

How would western music education get rid of the prejudice against music arts in Chinese social consciousness, gain acknowledgement and attention of modern Chinese people and the ruling class, and take the high road to enter the gate of Chinese higher normal education? At this moment, still some beneficial catalytic agents are required to move forward the wheel of the history.

\subsection{Popularization of school song}

At the time when imitating western school system and establishing a brand-new Chinese modern educational system, modern education reformists naturally will not ignore differences between oriental and occidental education in terms of content and subjects. Since the $22^{\text {nd }}$ Year (1896) of Kuang-hsu, Qing Government had sent students overseas to Japan year by year. After having witnessed and heard magnificent school songs that express feelings of all, these young patriots believed that was unprecedented in Chinese traditional education, which was exactly the appropriate way to save the nation and ensure its survival, reform the society and arouse the patriotic feeling of the great masses, so it was worthy of supplementing to modern Chinese education. Hence, either by investigation or by learning, they took a positive attitude to advocate and introduce the singing class in the school. Most of these young patriots, afterwards, became the first batch of musicians in modern China and became forerunners to stimulate Chinese music culture to transit to modernization.

The spiritual leaders of Reformers, Liang Qichao and Kang Youwei, were the first ideologists to mention music education in modern schols in China. As early as 1891, in his "Notes of Learning in Changxing", Kang Youwei clearly pointed out, "Students should develop themselves in coordination in terms of such aspects as morality, intelligence and physique, etc, and they should be trained in music, dance, physique and military gymnastics." For a special purpose, he wrote "Wencheng Song of Dance" to let students sing and dance with accompaniment of music accompanied by drumbeats in order to edify students' sentiment (Ma Dongfeng, 2001, p.208). In 1898, in his "On Learning of Children", Liang Qichao gave an introduction to music education in western schools, that is, "When westerners teach students, they will first of all teach them music to bail them out of boredom and to harmonize their vigour. Most of music is in the form of folk songs which are easy to read aloud and most of music is in the form of colloquial languages which are easy to understand. (Liang Qichao, 1983, p.148). At the same time, Liang Qichao attempted to publicize to national people the importance of music education. He pointed out, "If we wish to change the quality of our national people, then poem 
and music is one of the major elements for spiritual education" and "Unless we do not undertake education today, the subject of singing is really indispensable in school education" (Liang Qichao, 1983, p.148). Kang Youwei was the first person to propose to the Qing Government to set up class of music and song in the school. In his "Book Requiring to Open a School" submitted to the Qing Government, he mentioned, "Educational system of the Qing Government should learn from as far as France and Germany and as near as Japan", and "all towns should establish a primary school, and all citizens above the age of seven must go to the school to learn literature and history, arithmetic, geography, physics and music for eight years" (Shu Xincheng, 1961, p.148). Music here means the class of music and song opened in new schools.

It is just publicity and advocacy of Reformers ideologists that enabled music to step into the vision of modern educational reform. Thus, school song became the pioneer of modern music education and yielded brilliance to the history of modern Chinese education.

Since the release of "gui-mou school system", quite a number of schools and elementary education schools established by Chinese people began to open music and song classes. For example, in 1904, "Shanghai Longmen Normal School" set up music and song classes, two hours each week; in 1906, "Beiyang Woman's Normal School" started classes and opened "music and song" as a liberal subject, with distinction of monophonic sing and complex tone sing in the teaching content; "Hunan Elementary Education School" in Changsha set up classes of music and song, and in "An Introduction to Teaching in Elementary Education School in Hunan", detailed explanation was given to meanings and requirements of teaching in setting up classes of music and song, that is, "Music and song cultivates one's spirit with acoustics and rhythm, makes one dance accompanied to lyrics, activates ones' vein by portrait, and expresses one's feeling by one sing and three times of sigh... this is the goal of cultivation", and "schools without any music or song is merely teaching without education". (Sun Jinan, 2000, p.25), etc. By that time, overseas students who returned to China in succession after having learned western music in foreign countries also made particular contribution to the Chinese indigenization of the content of music and song. In 1904, Zeng Zhimin published "Collected Works of Songs of Education", which collected 26 musical songs; in 1905, Li Shutong published "Collected Works of Songs of Sinology", which collected 15 songs and 10 mixed songs were appended; in the same year, Shanghai Commercial Press published one volume of "Elementary Textbook of Sing for Primary School" with numbered musical notation; collected songbooks of school songs published in 1906 also included "Collected Works of Sing by Women" by Shou Lingni, "Textbook of Sing" by Xin Han, "Games of Sing" by Wang Jiliang and "Collected Works of Sing in Schools (Level 1 to Level 4), etc. (Sun Jinan, 2000, p.25). Creation of musical songs at the initial period mainly borrowed western tunes to fill in lyrics of China, and conveyed to students the advanced patriotism thought of a prosperous country with a powerful army by collective singing easy to pronounce. Publication of so many collected works of songs has given us a vivid view of the degree of recognition to school songs in China at that time and the extensive development of the class of sing in China.

When the whole society approved of schools songs, the Qing Government released "Women's Elementary School Constitution" in March 1907, finally categorized "music" as a liberal subject for elementary and higher schools for the first time, and specified "special teachers can be arranged for the single subject of music". In the same month, the government released "Women's Normal School Constitution", in which "music" was specified as a required subject in the four years, one hour each week the first two years and two hours each week the other two years (Shu Xincheng, 1961, p.797), which changed the previous situation when music had no position at all in the regulations of a school. Hence, school songs gained a rational status, got developed in a more comprehensive way and became a popular music behavior. The fundamental change of the status of music education in China implied that, as an independent entity, music arts had obtained its due position in educational field in China. The popularized development of school songs enabled musical quality of the national people to be gradually enhanced, and at the same time, training of teachers in special higher music education in was brought on the agenda. Thus, higher normal music education came into existence without extra effort. However, success of this effortlessness was owing to spending of almost thirteen years. The actual reason was that the traditional society of China was not profoundly aware of music arts, so real development of music education more need a theoretical escalation.

\subsection{Proposal of the aesthetic education theory}

Further exchange of Chinese and western culture in the earlier 1800s brought a turnover to the self-seclusion of modern Chinese culture, and as a matter of fact, learning of western academic theories was to help ourselves to extract and purify cultural spirit of Chinese tradition. The idea of aesthetic education had been in existence since ancient China, but was not given adequate attention to, and just survived in a natural way.

Wang Guowei (1877-1927), a great scholar with thorough knowledge of both western countries and Chinese, created modern aesthetic education theory by combining the speculative colour of western aesthetics and the intuitional characteristics of Chinese aesthetics, which laid a theoretical foundation for survival and development of modern music education in China. Wang Guowei pointed out, a primary issue in modern Chinese education was how to cultivate the 
spiritual interest of the national people. In order to resolve this problem, in his "On the Goal of Education", he mentioned in the same breath aesthetic education and morality, intelligence and physical education for the first time, which, without doubt, was an innovative action in the history of Chinese education. According to Wang Guowei, education should be classified into the two aspects of "spiritual education" and "physical education", the former including morality education, intelligence education and aesthetic education. The three aspects fulfilled in parallel the ideal of the true, the good and the beautiful, together with physical education, made a perfect person. (Feng Wenci, 1998, p.292). Wang Guowei regarded cultivation of "perfect people" as "the goal of education", whereas aesthetic education was an important component of "spiritual education", and it directly determined whether "perfect people" could be generated. His viewpoint altered the idea of Chinese traditional education, and endowed modern Chinese music education with significant social aesthetic functions. In "On Materials for Sing Subject of Primary School", he mentioned that the original idea of setting up the subject of sing lied in the three aspects of "reconciling emotion", "edifying one's will", and "linking intelligence organ and acoustic generator". "The first aspect and the third aspect are the career of the subject of sing itself, whereas the second aspect is the public career of the subject of cultivating one's moral character and the subject of sing". (Yao Quanxing, 1992, p.171). According to Wang Guowei, although the second aspect could assist the subject of cultivating one's moral character, it still had its own "independent position", but not merely "a slave of the subject of cultivating one's moral character". For the first time, Wang Guowei stated particularity and importance of music to the spiritual education of people from a theoretical perspective, and seriously pointed out the deserved independent status of "the subject of sing", namely, music education, which had extremely significant groundbreaking meaning to development of modern music education in China.

Another educator who attempted to publicize aesthetic education theory was Cai Yuanpei (1868-1940). Similar to the thought of Wang Guowei, the aesthetic thought of Cai Yuanpei also believed that, the purpose of education was to cultivate "perfect character" by means of moral education, intellectual education, physical education and aesthetic education, and that this conformed to the "republican spirit" of democratic revolution, that is, freedom and equality, universal love. In 1912, during the period when he held the position of Chief Minister of the Republic of China, Cai Yuanpei published an article entitled "Opinions on Educational Strategies", in which he mentioned five types of education should be carried out in the Republic times, namely, military citizenship education, meritocracy education, moral education, education of world outlook and aesthetic education. According to him, "any of the five types of education can be neglected", and especially, "merely education of world outlook and aesthetic education were not mentioned by you (Qing Government), whereas I pay particular attention to these two" (Chen Xuexun, 1983, p.327). Besides, Cai Yuanpei put forward the assumption of implementing aesthetic education in an all-round way from the aspects of family education, school education and social education. He asserted that children should go to kindergartens at the age of three and offered education in dance, singing, handwork and drawing. School education would not only include courses of music and arts, etc, but would add aesthetic education in teaching of all subjects; in addition, the implementation of aesthetic education could be realized by giving a concert and exhibition. However, in social education, aesthetic education institutions should be particularly set up, such as public facilities of art galleries, theaters and movie theaters, etc, and aesthetic edification could be realized by employing streets, parks and buildings, etc. Furthermore, in 1917, Cai Yuanpei gave the famous speech "Theory of Aesthetic Education Displacing Religion" in the theology association in Beijing, and he pointed out, "Pure aesthetic education can cultivate people's sentiment, endow them with gracious and pure habits, and eliminate the idea of harming others to benefit oneself." (Cai Yuanpei, 1983, p.338). Owing to a series of pioneering opinions of "replacing religion with aesthetic education", "saving the country with aesthetic education" and "art for human life" etc, Cai Yuanpei provided theoretical foundation of thoughts for a large batch of musicians and music educators at that time, and guided musical practice activities of music educational predecessors.

Proposal of aesthetic education theory pushed modern music education in China to step towards a new historical period. Profoundly influenced by western philosophical and aesthetic thought, Wang Guowei and Cai Yuanpei put forward aesthetic education theory based on western idealism philosophy and aesthetics, which run counter to the predominant and narrow artistic thought of "writings are for conveying truth" and "the way of the world and the heart of a human being" in ancient feudal society in China, and which free Chinese music arts from the long-standing status of dependency and gained independent brilliance, so it became rationally possible for Chinese modern music education to be comprehensively explored.

More emphasis was placed on music art education with development of school songs and proposal of aesthetic education theory. The new type of education that was rapidly developed in China was expanded in terms of scale increasingly, and demand on music teachers was also steadily on the increase. Especially, demand on teachers of higher music education could not be satisfied merely by the limited number of returned overseas students. At this time, higher normal music education had evolved into a vividly portrayed degree in China.

In September 1920, "Beijing Female Higher Normal School" set up in addition "the special (training) subject for music and sports", and the distinguished music Educator Xiao Youmei was appointed Director of the subject. At the beginning, 
the subject was grouped as follows: those selecting music as the major subject would have to take sports as the secondary subject and on the contrary, those selecting sports as the major subject would have to take music as the secondary subject, with a length of schooling for three years. Afterwards, recommended by Xiao Youmei, the special (training) subject for music and sports was changed into independent music subject, with a length of schooling for four years, in which the majors of piano, vocality, national music and theory-composition would be set up (Sun Jinan, 2000, p.60), with the primary task to cultivate professional music teachers. Although there existed disadvantages of experiences in terms of teaching approaches, Xiao borrowed directly the tradition of European professional teaching in their teaching philosophy, and became the initiator of higher normal music education in China.

In sum, it is with the original intention of borrowing and learning western music content and forms that higher normal music education in China started. With establishment of Chinese normal education in the reform of late Qing Dynasty, publicity of school song and aesthetic education theory, Chinese higher normal music education has entered well-reasonedly higher colleges and universities in China and occupies an important position in higher normal education.

\section{References}

Cai, Yuanpei. (1983). Theory of Aesthetic Education Displacing Religion, in Selected Works of Modern Chinese Education, edited by Chen, Xuexun. Beijing: People's Education Press, p.338.

Chen, Xuexun. (1983). Selected Works of Modern Chinese Education. Beijing: People's Education Press, p.327.

Chen, Xuexun. (1986). Reference for Teaching of the History of Chinese Modern Education. Beijing: People's Education Press, Part Two.

Feng, Wenci. (1998). A Chinese-Foreign Exchange History of Music. Changsha: Hunan Education Publishing House, p.292.

He, Zhaowu. (1980). An Intellectual History of China. Beijing: China Youth Press, p.535.

Liang, Qichao. (1983). Critique on poetry from the Icy Drinks Studio. Beijing: People's Education Press, p.58, p.77.

Liang, Qichao. (1983). On Learning of Children, in Selected Works of Modern Chinese Education, edited by Chen, Xuexun. Beijing: People's Education Press, p.148.

Ma, Dongfeng. (2001). Study on History of Music Education. Beijing: Jinghua Publishing House, p.208.

Shu, Xincheng. (1961). Data on History of Modern Chinese Education. Beijing: People's Education Press, Part One, p.148.

Shu, Xincheng. (1961). Data on History of Modern Chinese Education. Beijing: People's Education Press, Part Two, p.797-810.

Sun, Jinan. (2000). Chronology of Modern Chinese Music Education. Jinan: Shandong Friendship Publishing House, p.25, p.29, p.30.

Sun, Jinan. (2000). Chronology of Modern Chinese Music Education. Jinan: Shandong Friendship Publishing House, p.22, p.27, p.33.

Sun, Jinan. (2000). Chronology of Modern Chinese Music Education. Shandong Friendship Publishing House, p.60.

Yao, Quanxing. (1992). The Course of Aesthetic Education. Shanghai: Shanghai Academy of Social Sciences Press, p.171.

Zhang, Dan. (1963). Selected Works of Comments during the Ten Years before the Revolution of 1911. Beijing: Sanlian Bookstore, Vol. 2, No. 1, p.3.

Zheng, Guanying. (1998). The Crisis Awareness in Millennium. Zhongzhou Ancient Books Publishing House.

Zhou, Yutong. (1934). History of Chinese Modern Education. Companion Books Limited, p.137. 
Table 1. Fundamental educational situation from 1907 to 1909

\begin{tabular}{|c|c|c|c|c|c|c|}
\hline \multirow{2}{*}{} & \multicolumn{2}{|c|}{ Elementary school } & \multicolumn{2}{c|}{ Secondary school } & \multicolumn{2}{c|}{ Higher school } \\
\cline { 2 - 7 } & $\begin{array}{c}\text { Number of } \\
\text { schools }\end{array}$ & $\begin{array}{c}\text { Number of } \\
\text { students }\end{array}$ & $\begin{array}{c}\text { Number of } \\
\text { schools }\end{array}$ & $\begin{array}{c}\text { Number of } \\
\text { students }\end{array}$ & $\begin{array}{c}\text { Number of } \\
\text { schools }\end{array}$ & $\begin{array}{c}\text { Number of } \\
\text { students }\end{array}$ \\
\hline 1907 & 34650 & 918586 & 419 & 31682 & - & - \\
\hline 1908 & 41379 & 1192721 & 440 & 36364 & - & - \\
\hline 1909 & 51678 & 1532746 & 460 & 40468 & 110 & 20672 \\
\hline
\end{tabular}

